Meta

Journal des traducteurs

Translators' Journal

\title{
Conference Interpreting in the USSR: History, Theory, New Frontiers
}

\section{Gelij V. Chernov}

Volume 37, numéro 1, mars 1992

La traduction en Russie : théorie et pratique / Translation in Russia: Theory and Practice

URI : https://id.erudit.org/iderudit/002227ar

DOI : https://doi.org/10.7202/002227ar

Aller au sommaire du numéro

Éditeur(s)

Les Presses de l'Université de Montréal

ISSN

0026-0452 (imprimé)

1492-1421 (numérique)

Découvrir la revue

Citer cet article

Chernov, G. V. (1992). Conference Interpreting in the USSR: History, Theory, New Frontiers. Meta, 37(1), 149-162. https://doi.org/10.7202/002227ar
Résumé de l'article

On retrace l'histoire de l'interprétation en URSS, de 1928 jusqu'à la fin des années 1970. Les deux principales approches théoriques soviétiques relatives à l'interprétation simultanée sont ensuite présentées. L'article se termine avec des réflexions concernant la possibilité d'intégrer l'ordinateur dans la pratique de l'interprétation. 


\title{
CONFERENCE INTERPRETATION IN THE USSR: HISTORY, THEORY, NEW FRONTIERS
}

\author{
GeLIJ V. CHERNOV \\ Maurice Thorez Institute of Foreign Languages, \\ Moscow, USSR
}

\begin{abstract}
Résumé
On retrace l'histoire de l'interprétation en URSS, de 1928 jusqu'à la fin des années 1970. Les deux principales approches théoriques soviétiques relatives à l'interprétation simultanée sont ensuite présentées. L'article se termine avec des réflexions concernant la possibilité d'intégrer l'ordinateur dans la pratique de l'interprétation.
\end{abstract}

With the advent of PERESTROIKA and NEW THINKING, the cold war receding, contacts between East and West develop so rapidly that they tend to produce a conference boom and hence a considerably higher demand for conference interpretation. Yet, simultaneous conference interpreting did not come overnight from nowhere.

The first experiment in simultaneous conference interpreting in the USSR dates back to 1928, the VIth Comintern Congress. The interpreters with clumsy contraptions over their shoulders to support the mastodon microphones of the times occupied the armchairs on the platform under the rostrum. There were no telephones - he speaker's message reached the interpreters' ears directly [Hofmann: 20]. The first booths and headphones appeared in 1933 at the XIIIth Plenary Meeting of the Comintern Executive. In 1935 the introductory statement by I. Pavlov to the XVth International Congress of Physiology was simultaneously translated into French, English and German.

In the post-war period a group of Russian simultaneous interpreters from Moscow formed part of the conference interpreters' team servicing the Nuremberg Trials and another one participated in the Tokyo Trials of the Japanese war criminals.

An International Economic Conference serviced with simultaneous interpreting was conducted in 1952 in Moscow, employing over fifty simultaneous interpreters, mostly new recruits to the profession, with six conference languages: Russian, English, French, German, Spanish and Chinese. Here, a relay system with the so called "lead language," now quite extensively used in the USSR and East European countries, was introduced for the first time.

The lead language relay mode is a purely national ${ }^{1}$ system based on one native tongue common to all members of the team of simultaneous interpreters, which in fact serves as a "lead language" - the speaker using any of the interpreters' B conference working languages, i.e. the interpreters' foreign languages, would be translated into the lead language, Russian, for example, by the appropriate booth, which becomes the lead booth. It is then relayed into other working languages. Since there is no permanent "home language" booth, the number of booths equals the number of working languages minus one. There is one hitch, however, when this mode is employed: since in most cases you cannot foretell the language of the speaker and the whole relay chain cannot be prearranged, it becomes vital to hear the first words of the speaker to know the language he is using, and hence sometimes those very first words tend to get lost in relay. The 
system continues to be in use today, sometimes provoking heated debates on whether the interpreters should translate into their B language. ${ }^{2}$

Since then both the number of international conferences and the number of interpreters in the USSR have been growing in almost geometric progression, just as they have been in the world at large. The latest development in this area would be a possible introduction of simultaneous interpretation service in the Supreme Soviet (the Parliament) of the USSR and Supreme Soviets of Constituent Republics [Second Congress].

Since 1962 the United Nations Language Training Course in Moscow, at the Maurice Thorez Institute of Foreign Languages, set itself as a school where 5 to 7 simultaneous conference interpreters are trained annually for the Russian Booth of the UN Secretariat in New York, Geneva, and Vienna, as well as for Bangkok and Nairobi to translate into the interpreter's $A$ language from their $B$ and $C$ languages, i.e. from English and French and/or Spanish into Russian. This course is very efficient due to two factors: one - the entrance competition is very high (up to almost one hundred per vacancy) and two - the ten-month curriculum is based entirely on the United Nations materials including a number of supporting courses besides the actual simultaneous interpreting course.

A decade later, in 1971, a postgraduate Advanced Translating and Interpreting School at the same college introduced a two-year course of simultancous conference interpretation in an $\mathrm{A}$ to $\mathrm{B}$ and $\mathrm{B}$ to $\mathrm{A}$ language combination (plus $\mathrm{C}$ to $\mathrm{A}$ language combination, if so desired by the student) - for the Soviet Union's national needs.

A myth about simultaneous interpreting being always done exclusively out of one's $\mathrm{B}$ and $\mathrm{C}$ into one's A language (or the interpreter's native tongue) has been long since in circulation, as well as a "theory" about inadmissibility of interpreting through a relay, both the myth and the "theory" resulting in an arrogant conclusion about the lead language relay mode of simultaneous interpreting as an inferior system and the interpreters practising this mode as "second class citizens" in the profession. The essence of this "theory" was echoed in two articles in the popular Moscow annual publication TETRADI PEREVODCHIKA (Translator's Notebooks). Alexander D. Schveitser, a former practising conference interpreter and Soviet scholar in linguistics ${ }^{3}$, argued that interpretation through the relay ("two-stage translation") has a number of inherent flaws: that it tends to result in the reduction of the amount of information at the first stage and hence the loss of some essential information at the second stage, that any error at the first stage would necessarily be reproduced at the second stage, that the lead interpreter undergoes an additional stress due to specific requirements of lead interpretation, as well as possible technical difficulties of the kind mentioned above [Schveitser 1967: 82-86].

Chernov, on the contrary, argued that although Schveitser was right in principle about the flaws of the lead language relay mode the system became unavoidable when the number of working languages exceeded four and when rare or exotic [i.e. not usually used at international conferences] languages are employed. Although professing the direct $B$ to A mode, the UN Secretariat makes exception for the Chinese and Arabic languages where it is the Chinese and Arabic booths that supply the A to B translation from those two languages which are then relayed by all the other booths. Chernov offered two empirical formulae showing the number of language combination, required in the direct mode and the relay mode respectively: $\mathrm{L}(\mathrm{L}-1)$ and $2(\mathrm{~L}-1)$. It is easy to see that with a modest number of six working languages the difference is already quite noticeable: $6 \times 5=30$ as opposed to $2 \times 5=10$ [Chernov 1977: 51-58].

A rationale behind the A to $\mathrm{B}$ direction of translation was given by $\mathrm{Y}$. Denissenko of the Maurice Thorez Institute at the symposium on the Theoretical and Practical 
Aspects of Teaching Conference Interpretation at the University of Trieste in 1986 when he stressed the importance of complete understanding even at the expense of certain stylistic imperfections. As if to support the argument by Chernov, Mme Renée van Hoof, Director General of the Common Services of Conference Interpretation at the Commission of European Communities echoed thus Y. Denissenko's view:

With all the strange languages we work out of and into, with Greek, Danish and with Portuguese we do see very often that a Portuguese native speaker working into English understands so well the language he is supposed to convey that even with an accent in English it does not matter and he is better received at the receiving end than an interpreter working out of Portuguese who might not know so well a strange language in the European champ d'action. [Theoretical Aspects 1989]

By the mid-sixties, the psychological and psycholinguistic scientific community, including their Soviet colleagues, were ready to thrust their teeth into the when's and what's and why's of that newly discovered phenomenon of the almost impossible performance of yhe human mind. To begin with they began to ask themselves if it was really possible for a human to listen and to speak at the same time. Zoya A. Kochkina, a psychology postgraduate at the Maurice Thorez Institute, replied in the negative at the 1964 II Congress of the Society of Psychologists of the USSR, arguing that human attention could not be divided, that attention was a matter of "all or nothing" and that therefore the so-called simultaneous interpretation was not, in fact, simultaneous, that it was done "by condensing the message and speaking faster than the speaker" [Kochkina 1963].

Simultaneity studies began after the invention of the multichannel tape recorder and were done at roughly the same time by several researchers at the end of the sixties and the beginning of the seventies [Henri C. Barik in the United States and Canada 1971; D. Gerver in the United Kingdom 1974; Irina A. Zimnyaya and Ghelly V. Chernov 1970; Anatoly F. Shiryayev 1971; Ghelly V. Chernov 1978 - all in the Soviet Union]. The results obtained by various methods and on different equipment (including some specially designed for the purpose - Chernov) were amazingly similar: the average of 70 per cent of the interpreter's simultaneous listening and speaking, the total speaking time of the SL speaker being taken for 100 per cent. Yet, we believe that the most weighty Soviet contribution to the study and research into simultaneous conference interpretation was made on the theory of the process.

The Soviet school of thought on the underlying psycholinguistic machinery of simultaneous interpretation is actually represented by two approaches, both regarding simultaneous interpretation as a kind of verbal activity with specific features and carried out in specific conditions [Gh. V. Chernov 1978, 1987; A.F. Shiryayev 1979, 1982].

Shiryayev postulates that simultaneous interpretation as a specialized activity consists of STEPS or ACTIONS, each of which contains several stages. The most important stages are: stage of orientation (of unravelling, or sorting out what's what in the SL statement), stage of the search for, and making of, the translation decision and the execution stage. When the speaking rate in SL is slow enough stage one of step two follows stage three of step one - there is no simultaneity of listening and speaking, as a matter of fact. When the rate of speaking in SL is fast enough stage one of step two and stage three of step one coincide, stage three of step one becoming UNCONSCIOUS and 
AUTOMATIC, stage one, and probably two of step two being in the foreground, or in the focus of attention of the interpreter. Diagrammatically, actions fit in spoonlike with each other. According to Shiryayev [Shiryayev 1979: 106-112], the distribution of LEVELS OF AWARENESS of the stage is affected by the so called "synchronization mechanism," focusing the attention on the analysis and/or comparison of information, or the choice of a variant out of their possible multitude.

There is some doubt about the postulated "synchronization mechanism" since it is not explained, nor its existence demonstrated, it remains just a name, since levels of awareness obviously belong to the MECHANISM OF MONITORING the action and must therefore be separate from the mechanism of execution. Despite that rather basic flaw, the analysis of SI given by Shiryayev has a number of illuminating details pertaining to patterns of simultaneity, speech rates, methods of speech compression and syntactic transformations and some important psychological mechanisms.

It would only be natural that I should concentrate on my own model of the SI psycholinguistic machinery, which, as I will try to show, has a much greater explanatory force. Below I shall deal with the probability prediction model of the SI mechanism as its most essential factor explaining the simultaneity itself [Chernov 1978, 1979, 1980, 1987].

I regard the simultaneous interpretation (SI) as a complex type of bi-lingual, senseoriented communicative verbal activity (in contrast to both sense- and language-oriented translation) performed against time and with a strictly limited amount of information processed at an externally controlled pace. In such extreme circumstances only messages with an adequate degree of redundancy could be an object of simultaneous interpretation.

... Redundancy has its advantages, and a large degree of interdependence among the successive units of a language means that parts of the message can be lost or distorted without causing a disruption of communication. Any missing portions can be supplied by the receiver on the basis of the surrounding portions, on the basis of contextual clues [Miller 1963: 103].

As demonstrated by George Miller, redundancy in a communication boils down to (1) the iteration of message components and (2) their interdependence. Since both are objective factors, independent of the message recipient, that redundancy may be termed objective redundancy of the verbal message. At the level of the language acoustic material, or sound waves, redundancy is represented mostly as phonotactical interdependencies, as well as the iteration of the verbal message prosodic features. Within the framework of semantics (linguistic meaning) it should be appropriate to consider the level of the utterance, as against that of the complete communication (text, discourse).

At the level of the utterance, the first aspect of objective (speech) redundancy is represented as the iteration of semantic components, ensuring semantic and grammatical agreement in discourse [Apresyan 1974]; semantic interdependence is represented as semantic government. At the level of discourse (text) the first aspect is represented as anaphoric repetitions and co-reference in discourse, the second - as the coherence of the text. The first aspect reflects the topical (thematic continuity of the text, the second - a number of specific rules of semantic constraints of the type formalized by Wallace L. Chafe [Chafe 1972].

The above factors can be presented as a table. 


\begin{tabular}{|l|l|l|l|}
\hline $\begin{array}{l}\text { redundancy } \\
\text { factors } \\
\text { information }\end{array}$ & \multicolumn{2}{|c|}{$\begin{array}{c}\text { representation in discourse } \\
\text { by levels }\end{array}$} & $\begin{array}{l}\text { philosophical } \\
\text { essence of the } \\
\text { phenomenon }\end{array}$ \\
\cline { 2 - 4 } & utterance & $\begin{array}{l}\text { coherent } \\
\text { communication }\end{array}$ & probability \\
\hline repetition & $\begin{array}{l}\text { iteration of } \\
\text { semantic } \\
\text { components } \\
\text { and their } \\
\text { configurations: } \\
\text { agreement }\end{array}$ & co-reference & certainty \\
\hline interdependence & $\begin{array}{l}\text { semantic } \\
\text { interdependence: } \\
\text { predicate- } \\
\text { object and } \\
\text { modifier relations }\end{array}$ & $\begin{array}{l}\text { semantic } \\
\text { constraints }\end{array}$ & \\
\hline
\end{tabular}

On the other hand, a communication is subjectively redundant for the message recipient. To make the difference tangible I propose to make the following distinction between the linguistic meaning and extralinguistic sense. I suggest that the process of language comprehension is based on a purely human capacity for making inferences. Whatever is inferred by the hearer is inferred about the sense of each utterance and the part of discourse already produced. Considering the source of the inference, inferences can be classified into linguistic, cognitive, situational, and pragmatic.

I have been developing an unorthodox view that the notion of both presupposition and linguistic implicature are borrowed from one and the same source - the logical implication of the form "if A, then B," presupposing both the explicit antecedent A and the explicit consequent $B$. I suggest that a third term be introduced into the binomial formula of material implication in order to account for the difference between the linguistic presupposition and the linguistic implicature: $(\mathrm{A}) \rightarrow \mathrm{B} \rightarrow(\mathrm{C})$, to be read "if A (implicit), then B (explicit), if B (explicit), then C (implicit)," where B is the explicit term to be found verbally expressed in the text of the message, while the terms $A$ and $C$ are only implied. In that case (A) as an antecedent for B is its presupposition (which determines the sense of the message) and (C) as its implicature, or the inference drawn by the recipient of the message from the explicit utterance of B [Chernov 1988].

LINGUISTICS INFERENCES can be drawn about the referential component of the semantic structure of the utterance (discourse) for example, from pronominal coreference, co-reference based on the common componential stock (SELL contains the component "money," hence after the appearance of the verb SELL in discourse the noun MONEY will follow with a definite article), or semantic government (HE LEFT MOSCOW FOR LENINGRAD implies that "HE IS NOT IN MOSCOW ANY MORE," that "HE IS PROBABLY IN LENINGRAD" or "... ON HIS WAY THERE"). Any component of the semantic structure of the text could become a source of a linguistic inference (e.g. WE HAVE BEEN IMPRESSED BY... - the inference is: whatever impressed us must be "POSITIVE" or "GOOD" - assessment; MY DELEGATION HAS WORKED TOWARDS AN OUTCOME... must be followed (a linguistic inference) by a non-factive proposition [cf. Lyons 1977: 816-818], ... REFLECTING A CONSENSUS, ... WHICH WOULD REFLECT A CONSENSUS, but not ... ${ }^{*}$ WHICH REFLECTED A (THE-?) CONSENSUS - factivity). 
The formalization of a semantic constraint, suggested by W. Chafe [cf. Chafe, ibid.] may serve as a basis for a formal representation of a linguistic inference: Chafe's formula $\mathrm{X} \rightarrow \mathrm{Y}$ to be read "X entails $\mathrm{Y}$," or consequently "if $\mathrm{X}$, then $\mathrm{Y}$," means also that "the hearer's knowledge of $X$ implies his knowledge of $Y . "$ Thus, a semantic constraint which is an objective factor of redundancy becomes a subjective factor of linguistic inference for a given hearer, drawn on the basis of his/her knowledge of the language spoken. Chafe's semantic constraint forms a part of the following contextual rule

$$
\mathrm{W}: \mathrm{X} \rightarrow \mathrm{Y}: \mathrm{Z}
$$

to be read "the presence of the semantic element $W$ introduces the constraint $X \rightarrow Y$, which remains in force up to the point where $Z$ appears, where it will then evaporate" [Chafe, op. cit.: 48].

The COGNITIVE INFERENCE is made by the hearer when in order to make sense the semantic elements of the utterance (or the part of the discourse) already produced must interact with the background knowledge of the hearer. To understand the utterances and

$$
\text { HE STUDIED AT ETON }
$$

\section{HE STUDIED AT COLUMBIA}

one must have the appropriate background knowledge about the Eton College in the United Kingdom and Columbia University in New York. In fact, J. Searle [Searle 1979: $120]$ argues that

the notion of the literal meaning of a sentence only has application relative to a set of background assumptions, and... these background assumptions are not all and could not all be realized in the semantic structure of the sentence... [Cf. also his example of THE CAT IS ON THE MAT.)

The linguistic and cognitive inferences are very often intertwined and sometimes are even inseparable.

SHE COULDN'T COME BECAUSE OF HER MOTHER supplies a source of a linguistic inference about the reason of HER ABSENCE which is rather vague, and a more specific cognitive inference depending on specific circumstances: ...BECAUSE HER MOTHER CAME TO SEE HER, ...WAS SICK, ...ASKED HER TO DO SOMETHING, etc.

At least one case of such a dependence could be formalized in the form of a semantic (and sense) constraint:

$$
\begin{aligned}
& \begin{array}{lll}
\mathrm{W} & : \mathrm{X} \rightarrow \\
\text { object } & \text { part of } W
\end{array} \quad \text { definiteness of } \mathrm{X}: \quad \text {. } \\
& \text { phenomenon feature of } \mathrm{W} \\
& \text { cause consequence of } W
\end{aligned}
$$

to be read as follows: if an object, or a phenomenon, or a compelling reason are mentioned in a coherent discourse any subsequent mention of an integral part of that object, or an inherent feature of the phenomenon, or an inescapable consequence of that reason, is normally accompanied by a sign of definiteness (a definite article in languages that have them at all), reflecting the presupposition of concurrent existence of the object and its part, etc. (That should take care of formalizing Chafe's examples about the bicycle - see op. cit., p. 62.) 
There is however distinct evidence to support positing separate entities as linguistic and cognitive types of inferencing performed during simultaneous interpretation. For instance the perception of the following utterance

\section{THIS ASSEMBLY HAS INCREASINGLY TURNED ITS ATTENTION TO THE GREAT PROBLEM OF DISPARITY BETWEEN THE STANDARDS OF LIVING OF THE DEVELOPING AND DEVELOPED COUNTRIES}

is approximately such, as evidenced by three translations into Russian (out of eleven done during the experiment):

... PROBLEM OF ... GAP BETWEEN LEVEL (1) OF LIFE ... OF DEVELOPED COUNTRIES ... AND LEVEL (2) OF LIFE OF DEVELOPING COUNTRIES, ... AND LEVEL (1) IS HIGH... (WHILE)... LEVEL (2) IS LOW. [Cf. Chernov 1987: 103-104]

The SITUATIONAL INFERENCE about the sense of the utterance (or the part of the discourse) produced has the communicative situation as the source of the inference. For example, from the speaker's address "Mr. President..." an inference drawn situationally may establish a reference to the President of a country, or the President of the UN Security Conference (... for the month of..., representing country X..., etc.), or the president of a college, etc. It is the situational inference that turns the interrogative sentence "Could you pass me the salt? into a speech act of making a request [Cf. Searle 1979]. factors:

An analysis of the communicative situation of SI involves eight clearly identifiable

- the characteristics of the message source, or speaker (S), obtained from a reply to the question "Who is speaking?";

- the theme of the message (T) - "what is he talking about?";

- he relation of the act of speech to the event that provoked it $(E)$ - "in what connection is he speaking?";

- the message recipient, or audience (A) - "whom is he addressing?";

— the place, or forum $(\mathrm{F})$ - "where is he speaking?";

— the time (T) — "when is he speaking?";

- the purpose of the communication (P) — "what is he aiming at?";

— and its motive (M) - "why is he speaking?" [Chernov 1975, 1978, 1987].

The PRAGMATIC INFERENCE from an utterance is made when the hearer draws conclusions about the speaker, above all, about his/her social role, on the basis of the utterance's semantic contents, his own background assumptions and knowing the factors of the communicative situation. Besides a brief case study related to the matter [Sladkovskaya 1971] there are practically no publications on the subject available either in the Soviet Union, or in the West. I believe, however, that sociolinguistic studies of the social role played by the participants in an act of communication and, specifically, experimentation in the deviation from the expected role, may prove to be especially revealing.

Redundancy at all levels, both objective semantic redundancy and the subjective redundancy at the level of sense make for and, indeed, signify the predictability of meaning and sense in the message. Redundancy of an average verbal communication, at least in the languages that have been studied from that angle, is high enough to warrant a suggestion that the difference in message redundancy of different texts lies between the values of 80 and 95 per cent and not between 0 and 100 per cent. A highly redundant text (oral communication) - as most of them are - is predictable. Hence, the machinery of probability prediction, or to be more exact, the prediction of the probability of certain 
linguistic (phonetic, prosodic, verbal and syntactic) or semantic (meaning and sense) developments of the utterance and complete communication at the stage of reception (communication between the speaker and the interpreter) and anticipatory synthesis of the TL (target language) message. This machinery, in fact, makes it possible to perform the concurrent perception and understanding (inferencing) of the SL communication, on the one hand, and reproduction (generation) of the TL message, on the other, or simultaneous interpreting. This model is based on a fundamental methodological notion, according to which living matter reflects reality in anticipation of events in the outside world, this being a "basic form of adjustment of living matter to the spatio-temporal structure of the inorganic world in which the sequentiality and iteration of events constitute the basic parameters of time" [Anokhin 1968, 1978]. According to P.K. Anokhin, the human "central nervous system developed as a mechanism of maximal anticipation of sequential and iterative phenomena of the outside world at the greatest possible speed" [Anokhin 1978] and the anticipatory reflection of reality is a universal natural law of which the Pavlovian theory of conditioned reflexes is only a specific case.

Information content, or redundancy, is not distributed in a uniform manner throughout the communication. Redundancy is concentrated in the THEMATIC, or TOPICAL, part of each utterance while information is at its greatest density at the RHEME of the utterance. Hence, a possibility of compressing speech in various ways in the thematic part of the utterance - by reducing the number of syllables, or words, or semantic components, by simplifying syntactical structures. A case of translating a chairman's announcement:

I now give the floor to the distinguished delegate of the United Republic of Tanzania!

by a simple

Tanzania!

exemplifies the situational compression which covers the reduction of the number of syllables, the number of words, deleting the entire thematic part of the utterance and simplifying the syntactical structure to a single word. In fact, only the rheme of the utterance remains after the performance of an act of compression.

Comparison of the number of syllables of the original communication (in Spanish) with the number of syllables in TL in the recorded pieces of simultaneous interpretation (translated by two interpreters each during the 1978 United Nations experimental remote interpreting via satellite with the parallel control group of interpreters working in the conference room) shows a strong tendency towards compression as seen from the following figures.

The passage of 11 sentences

\begin{tabular}{|c|c|c|c|c|c|c|}
\hline \multirow{3}{*}{$\begin{array}{l}\text { of the Spanish original } \\
\text { Syllables: }\end{array}$} & \multicolumn{2}{|c|}{ Russian } & \multicolumn{2}{|c|}{ English } & \multicolumn{2}{|c|}{ French } \\
\hline & 1 & 2 & 1 & 2 & 1 & 2 \\
\hline & 689 & 676 & 539 & 545 & 537 & 617 \\
\hline
\end{tabular}

There is every reason to presume that in order to perceive the information flow to the brain from the outside world, the brain forms a special neurophysiological mechanism ensuring above all the perception of the measure of information change. I may recall, for example, that figures are identified by a human by the perception of the maximum curvature points, that moving objects are given priority in perception (see the structure of a frog's eye, or the necessity of an eye movement and fixations to identify features of objects) [Perception 1972]. May I also recall that phonemes are as a rule recognized not so much by a steady-state segment of the sound pattern as by a transition stage (according 
to D. Massaro [Massaro 1975], in order to perceive the CV type of syllable of the average of $200 \mathrm{msec}$ duration one needs only $42 \mathrm{msec}$, of which $30 \mathrm{msec}$ of transition and only 12 msec of the steady-state segment).

One can easily argue that understanding meaning and sense is subject to a similar law of perception, that attention is primarily focused on those semantic components that carry new information, and that is exactly what the rheme is about. In other words, I believe that the interpreter's attention is drawn above all by the rheme of the utterance. Any misperception or loss of an item in the thematic, or redundant, part of the communication can be easily restored and is in the worst case a matter of quality of interpretation, while the loss of a rhematic item may easily result in mistranslation.

The levels of probability prediction machinery are based on redundancy growing from the level of the syllable to that of the word, phrase, utterance, communication (text) and situational context. The object of probability prediction (what is predicted) is a source of four-tier classification, among which all the levels can be distributed.

Sound patterns (as syllables, encoding phonemes, and intonation and stress, and other prosodic features) are anticipated and perceived at the "lower" tier encompassing the levels of the syllable, the word, the phrase and the utterance. (Redundancy at those levels has been quite extensively analyzed in psychology.)

Grammatical (syntactical) and, more generally, categorial semantic features are anticipated and/or perceived at the next tier encompassing the levels of the phrase and the utterance.

Tier three - the semantic tier proper - covers the levels of the phrase, the utterance and the text, and constitutes the central or the pivotal tier of the probability prediction machinery in simultaneous interpretation.

The highest tier of probability prediction, corresponding to the highest level of subjective redundancy - inferring the sense and anticipating the probability of its further development in the message (the sense tier proper) - embraces the levels of the utterance, the text, and the communicative context.

Close interplay and interaction of the levels begins at the moment actually preceding the beginning of the speech, when the speaker is given the floor.

If the speaker is known to the interpreter, by the moment the speech begins the interpreter forms a general outline of a probability prognosis of the meaning and sense structure of the forthcoming communication, supported by some knowledge of other factors of the situational context. Such a prognosis may be called the top-to-bottom prognosis carried out at tier four - the sense tier. The next step of the probability prediction process is carried out at the sound pattern tier, i.e. from the bottom upwards, after which the syntactical and semantic tiers are immediately involved.

If the speaker is unknown to the interpreter and very little or nothing at all is known about the situational context in general, the probability prediction process begins at stage two.

As the message develops (as a rule, in the course of the first several utterances), a general outline of a probability prognosis of the whole message (or its first thematic part) is formed in the mind of the interpreter, the levels described interacting (if they do not, errors and omissions appear in the TL communication). As the meaning and sense structure of the message develops, the field of the forecast of the forthcoming sense and even of the purely linguistic features of the communication narrows down at times to a certainty (the probability equalling 1). When a new subject is introduced by the speaker, the process will begin anew.

Probability prediction is facilitated by that internal programmes (Plans, in the terminology of [Miller, Galanter and Pribram 1960] of the utterances (as soon as they are 
ready) are carried out subconsciously as automatic operations and require little attention, if any, for the feed-back process. If difficulties of perception occur (due to a high level of noise or a rapid rate of speech resulting in low perceptional redundancy at the lower levels of the mechanism, or to complicated syntactical structures or syntactical errors in the SL discourse, yielding low redundancy at the syntactical tier, or due to unknown terminology, or sense gaps requiring more intense internal inferencing activity, or references to facts and events unknown to the interpreter, resulting in low redundancy at the semantic and sense tiers) the attention is fully switched over to perception and comprehension and the TL communication produced by the interpreter remains unchecked throughout. In cases like those the simultaneous interpreter becomes unconscious of his own TL communication: he may translate and speak without errors, but if errors and/or omissions occur, they remain uncorrected [Gerver 1975; Chernov 1978]. And vice versa, when the overall level of redundancy is adequate and the conditions of perception are favourable, attention may be fully directed towards monitoring the process of speech production in the target language. Interpreters know that in such cases they may lose awareness of the source language altogether.

The probability prediction model of SI, which models perception in discrete portions, by information density peaks, or points of reference, presupposes the identification of those points of reference at each level and tier. In fact, I have experimentally shown such points of reference in speech perception in SI for the level of the utterance (the rheme) and for the level of the situational context (factor S - "the speaker"). My colleague Sofia Lukanina [Lukanina 1974] has demonstrated syntactical points of reference in SI.

Our model presupposes 1) concurrent operation of the probability prediction machinery at several levels at each given moment, in time, 2) multichannel information processing, 3) heuristic interplay of levels from the bottom upwards and from the top downwards, as the message is scanned for information density peaks, above all at the sense tier. All those activities zero in on the sense of each utterance and of the communication as a whole, as it is perceived and transformed into the internal plan of the sense structure of the TL message.

The involvement as completely as possible, of as many levels as possible concurrently, constitutes a major factor of reliability of the communication process via simultaneous interpretation. In order to be effective, this step-by-step machinery must operate at higher (sense) levels, on the one hand, while, on the other hand, the probability prediction steps should be sufficiently discrete.

The following chart illustrates the results obtained as a function of the levels engaged concurrently. 
CONFERENCE INTERPRETATION IN THE USSR

159

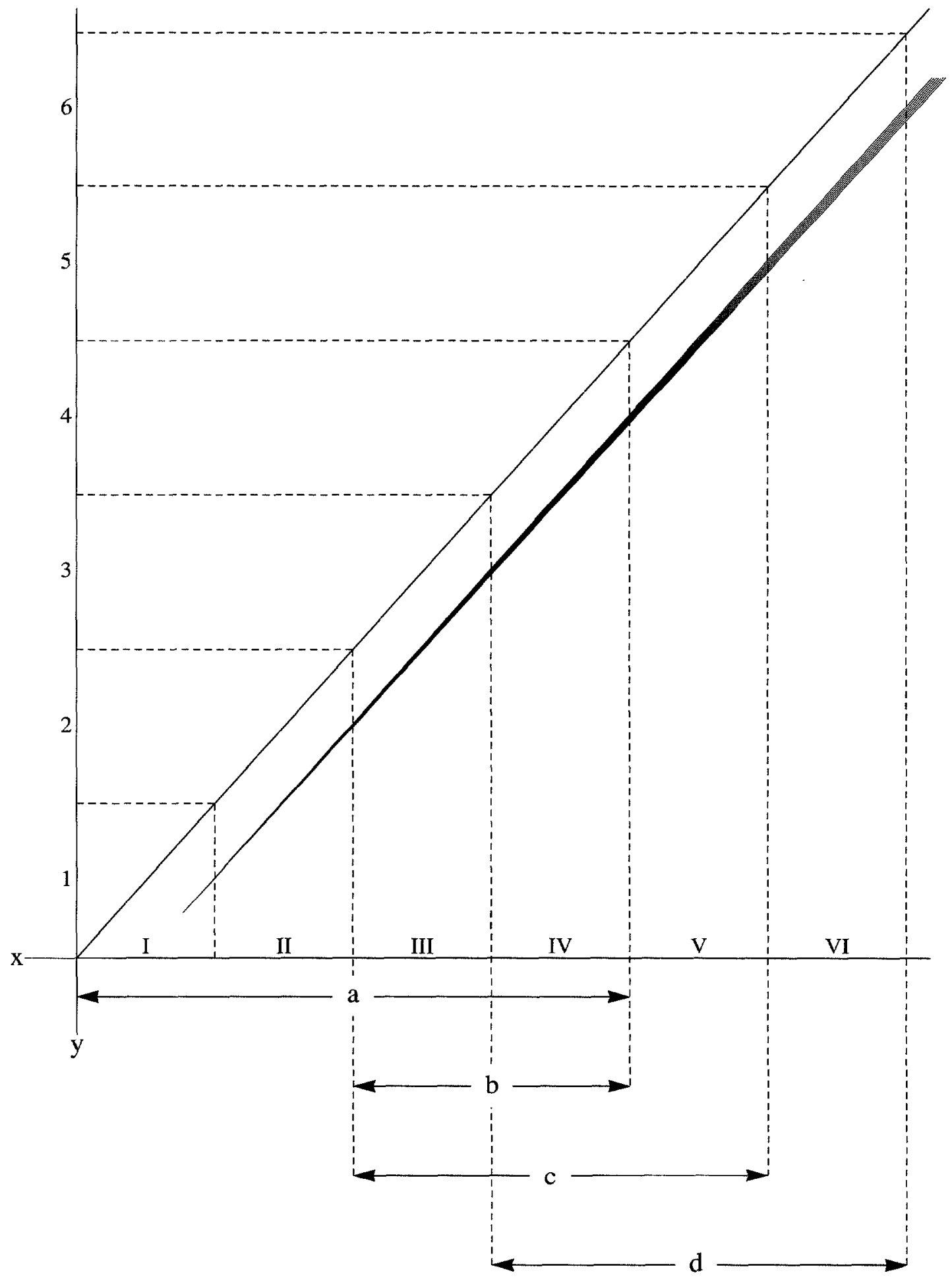


The chart illustrates the following idea: if, for the sake of argument, the interpretation could be carried out at the level indicated by the Roman numeral on the chart a 1 o $\mathrm{n}$, this would produce a result indicated by the Arabic numeral. The Roman numeral indicates the step of the prognosis for a syllable (I), a word (II), a phrase (III), an utterance (IV), a communication (V), and the situational context (VI). The Arabic numeral indicates the result obtained: 1 ) no translation, 2) rendering of the prosodics of an unknown word (e.g. an unknown proper name) or separate words (the sense arrived at accidentally), not connected in a coherent utterance, 3) disconnected phrases, 4) incomplete rendering of disconnected utterances, 5) a mere summary of the message, 6) the explication of the theme, the purpose of the communication and its underlying motives. The letters indicate the tier of the prognosis: a) prosodic, b) syntactic, c) semantic, d) sense.

Our model explains why simultaneous interpretation can only be applied to communications characterized by an adequate level of redundancy and cannot be applied to fiction and poetry. Explaining as it does certain inherent limitations on SI, it permits of a number of applications both in the field of interpreters' training and in the field of SI management at international conferences by conference secretariats.

It is only through conservatism of various conference services as well as AIIC in the West and similar associations in the East being on guard against any innovations that have at least a remote possibility of undermining the honorariums of practising interpreters by facilitating the conditions of their work that the advent of the AGE OF THE COMPUTER by-passed simultaneous interpretation. Yet there are a number of interesting possibilities of marrying the computer to the profession of simultaneous interpretation.

A computer assisted simultaneous interpretation booth (SIBCACH $=$ Simultaneous Interpretation Booth, Computer Assisted, by Chernov) should have several new features. For example, I suggest that a new booth should be equipped with a computerized dictionary (COMPUDIC), containing at least 1) a basic conference procedure phrase book (adjustable for language combinations in the working languages of the conference and/or the international organization), 2) SI type of special terminology glossaries for the given conference (certain experience of compiling such glossaries [Chernov 1990] has been accumulated by the author while serving as Chief of Russian Interpretation Section at the United Nations Secretariat in New York, among their characteristics being that they should be quite concise - of about one hundred carefully selected items; that they should be besides thematic glossaries also typical situation glossaries, or speaker-oriented glossaries) that could be easily - with no more than two-letter of two-digit combination - retrieved on a booth computer display, 3) brief background conference reference materials as e.g. names of delegates, co-ordinated with bodies they represent, etc.; lists of related national and/or international bodies often mentioned by delegates, and so on. Work on such a dictionary on a PC is now in progress in Moscow [Chernov 1990].

An automatic "SI quality control" device could become another new feature of a computerized SI booth (AQUACON = Automatic QUAlity CONtrol). According to my previous findings [Chernov 1973], there seems to be an OBJECTIVE and INDEPENDENT TEMPORAL PARAMETER of the quality of interpretation, in terms of how complete the rendering of the sense of the SL message is in the TL message. The parameter is based on the phenomenon of relative hesitation in human speech in terms of 
time (the relation of pause to actual speech time in discourse: $P: S$ ). The parameter describes relative verbal density in the interpreter's speech relative to the verbal density in the speech of the SL speaker. The parameter may be expressed as:

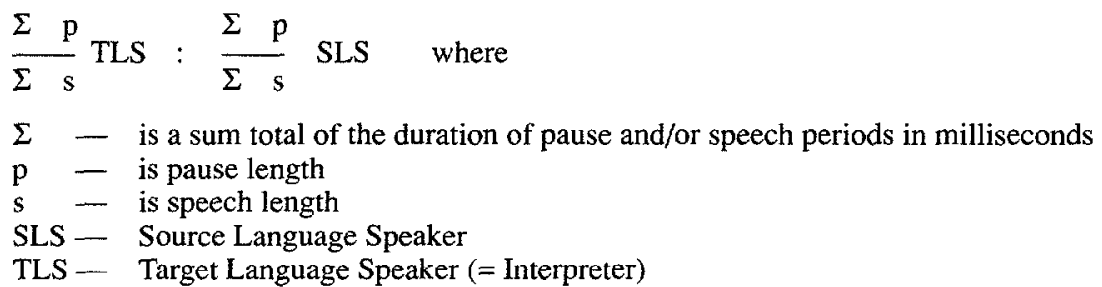

According to available findings [Chernov 1973], the ratio of interpreter's relative hesitation (or verbal density) to that of Speaker equals or is more than 0.8 when the quality (in terms of rendering the meaning and sense structure of the TL message) of interpretation is satisfactory, and less than 0.8 when the quality is inadequate.

Since the parameter can be easily obtained automatically and displayed, e.g. as a red light in case RELATIVE VERBAL DENSITY is less than 0.8 , a yellow light in case the value of the parameter is in the area between 0.8 and 1.0, or a green light, if it is 1.0 or higher.

The analysis of additional material to substantiate available statistics is now being arranged to obtain more reliable statistical data.

Those are just a few of the possible new features of an improved standard for a simultaneous interpretation booth. There is also some linguistic research in SI currently underway here.

Notes

1. As compared to an international team of the kind working for a United Nations meeting, where the number of booths would equal the number of working languages and each booth would take care of interpreting into their mother tongue out of all other working languages.

2. Below I shall discuss some of the principles of interpreting from one's A to one's B language or vice versa as well as the necessities and demerits of a relay mode of simultaneous interpreting, as seen in the Soviet Union.

3. Cf. his works on the American English, theory of translation and sociolinguistics.

\section{BIBLIOGRAPHY}

ANOKHIN, P.K. (1968): The Biology and Neurophysiology of the Conditioned Reflex. Moscow (in Russian). ANOKHIN, P.K. (1978): The Philosophical Aspects of the Functional System Theory. Moscow (in Russian). APRESJAN, Y.D. (1974): Lexical Semantics. Moscow (in Russian), 345 p.

CHAFE, Wallace L. (1972): "Discourse Structure and Human Knowledge," in Language Comprehension and the Acquisition of Knowledge (Eds. Freedle, R.O. and Carroll), New York, Toronto, etc.: V.H. Winston and Sons, pp. 41-70.

CHERNOV, G.V. (1973): "Towards a Psycholinguistic Model of Simultaneous Interpretation," in Linguistische Arbeitsberichte, Leipzig (in Russian).

CHERNOV, G.V. (1975): "The Communicative Situation of Simultaneous Interpretation and Message Redundancy," in Tetradi Perevodchika, no 12, Moscow, pp. 83-101 (in Russian).

CHERNOV, G.V. (1977): "Once again on the Mode of Simultaneous Interpreting," in Tetradi Perevodchika, no 14, Moscow (in Russian).

CHERNOV, G.V. (1978): Theory and Practice of Simultaneous Interpretation. Moscow, 200 p. (in Russian).

CHERNOV, Ghelly V. (1979): "Semantic Aspects of Psycholinguistic Research in Simultaneous Interpretation," Language and Speech, Vol. 22, Part 3, pp. 277-295.

CHERNOV, G.V. (1980): "Semantic Redundancy as a Key to Reliable Comprehension of a Verbal Message," in Comprendre le langage. Actes du colloque de septembre 1980. Paris: Didier Érudition, pp. 31-37.

CHERNOV, G.V. (1987): Fundamentals of Simultaneous Interpretation. Moscow: Vysshaya Shkola, $156 \mathrm{p}$. (in Russian). 
CHERNOV, G.V. (in press) (a): "Cognitive and Pragmatic Inferencing and the Intercultural Component in Translation," in The Proccedings of the TRANSIF Seminar on Empirical Research in Intercultural Studies and Translation. Savonlinna, Finland.

CHERNOV, G.V. (in press) (b): Glossary for a Simultaneous Interpreter. (A page from the history of Russian Interpretation Section at the UN Secretariat.) Transactions of M. Thorez Moscow Institute of Foreign Languages, Vol. in press (in Russian).

GERVER, D. (1975): “A Psychological Approach to Simultaneous Interpretation," META, Vol. 20, pp. 119-128.

HOFMANN, Eu. (1963): "A Contribution to the History of Simultaneous Interpretation," Tetradi Perevodchika, no 1 . Moscow, pp. 20-26.

KOCHKINA, Z.A. (1963): "Some Specific Features of Activity of a Simultaneous Interpreter," The II Congress of the Society of Psychologists. Abstracts of Papers, Vol. 1. Moscow: Academy of Pedagogical Sciences (in Russian).

LUKANINA, S.A. (1974): "On a Mechanism of Handling Syntactic Information in Simultaneous Interpretation," Tetradi Perevodchika, no 11. Moscow, pp. 87-91 (in Russian).

LYONS, John (1977): Semantics, Vol. 2. Cambridge, etc.: Cambridge University Press, pp. 816-818.

MASSARO (1975): Understanding Language. An Information-Processing Analysis of Speech Perception, Reading and Psycholinguistics. Ed. by Dominic W. Massaro. New York, etc.: Academic Press.

MILLER, George A. (1963): Language and Communication. New York, Toronto, etc.: McGraw-Hill Book Company, Inc., $275 \mathrm{p}$.

MILLER, G.A., E. GALANTER and K.H. PRIBRAM (1960): Plans and the Structure of Behaviour. New York: Holt, Rinehart and Winston.

PERCEPTION (1972): Mechanisms and Models. Compiled by R. Held and W. Richards, MIT. San Francisco: W.H. Freeman and Co.

SCHVEITSER (1967): "On the Most Rational Mode of Simultaneous Interpreting," Tetradi Perevodchika, no 4. Moscow, pp. $82-86$ (in Russian).

SEARLE, John R. (1979): Expression and Meaning. Cambridge, Cambridge University Press, 179 p.

Second Congress of People's Deputies of the USSR XIIIth Session. Records of Proceedings. IZVESTIA, no 356, 22 December 1989, p. 4.

SHIRYAYEV, A.F. (1979): Simultaneous Interpretation. The Activity of a Simultaneous Interpreter and Methods of Teaching Simultaneous Interpretation. Moscow.

SHIRYAYEV, A.F. (1982): The Picture of Verbal Processes and the Translation. In Translation as a Linguistic Problem, N.K. Garbovsky (Ed.). Moscow University Press, pp. 3-12.

SLADKOVSKAYA, E. (1971): "Anticipation at the Level of the Purpose of Communication," Tetradi Perevodchika, no. 8. Moscow, pp. 61-64 (in Russian)

The Theoretical and Practical Aspects of Teaching Interpretation. L. Gran and J. Dodds (Eds.). Udine: Companatto Editore. 